Galina M. Vikhreva, Ph. D. in Pedagogics State Public Scientific and Technical Library of the Siberian Branch of the Russian Academy of Sciences (Novosibirsk, Russia) vihreva@spsl.nsc.ru

Olga P. Fedotova, Ph. D. in Pedagogics State Public Scientific and Technical Library of the Siberian Branch of the Russian Academy of Sciences (Novosibirsk, Russia) fedotova@spsl.nsc.ru

\title{
RESOURCE-BUILDING OF A MODERN LIBRARY AS AN OBJECT FOR PROFESSIONAL UNDERSTANDING
}

\begin{abstract}
The paper discloses the key approaches to understanding of current transformations in ideology and technology of resource-building of a today's scientific library developed by workers of the State Public Scientific and Technical Library of the Siberian Branch of the Russian Academy of Sciences (Novosibirsk, Russia). Cognitive value of involving methodological toolset elaborated by various scientific disciplines to dealing with problems of stock science, in particular problems related with indicators of document selection for a library fund, is argued. The authors outline their own opinion on current issues in elaborating of hierarchical system of priorities in forming, using, and preserving of multi-format documents in a today's Russian academic library.

Key words: an academic library, research activity in a library, informational resources of a library, multiformat documents, paper document, e-documents, depository storage, indicators of library selection, information environment, philosophy of a new library, library education.
\end{abstract}

УДК 027.2:6(571):021.63

DOI: $10.32340 / 2414-9101-2019-3-78-82$

T. В. Дергилёва, кандидат педагогических наук Государственная публичная научно-техническая библиотека Сибирского отделения Российской академии наук (Новосибирск, Россия) dergileva@spsl.nsc.ru

\section{АКАДЕМИЧЕСКИЕ БИБЛИОТЕКИ В СВЕТЕ ТРАНСФОРМАЦИИ И ЦИФРОВИЗАЦИИ НАУКИ}

Аннотация. Организационные преобразования государственных академий наук в России, организация федеральных исследовательских центров в системе Федерального агентства научных организаций повлекли за собой серьёзные структурные изменения академического сектора отечественной науки, приведшие к смене концептуальных основ организации информационного сопровождения научных исследований и ставшие причиной прекращения финансовой поддержки комплектования фондов центральных научных библиотек российских академических систем. Министерством науки и высшего образования Российской Федерации взят курс на интенсивную интеграцию цифровых технологий в отрасли научного знания. Автор характеризует основные тенденции информационного сопровождения научного труда на анализе опыта работы библиотечной системы Сибирского отделения Российской академии наук (г. Новосибирск, Россия); констатирует обратно пропорциональную зависимость между использованием учёными удалённых электронных ресурсов и востребованностью ими комплекса информационно-библиотечных и справочно-библиографических услуг.

Ключевые слова: научные учреждения, научные библиотеки, академические библиотеки, структура библиотечных систем, информационное обеспечение науки, иифровизация науки. 
Реформа Российской академии наук (далее - РАН) кардинально изменила академический сектор науки. Произошла интеграция трех академий: РАН, академии медицинских (РАМН) и сельскохозяйственных наук (РАСХН). Все научно-исследовательские учреждения (далее - НИУ) в 2013 г. были переподчинены Федеральному агентству научных организаций России (ФАНО России ${ }^{1}$ ), а затем в 2019 г. - Министерству науки и высшего образования Российской Федерации 2. Продолжается реструктуризация научных учреждений. На принципах объединения разнопрофильных НИУ организовываются Федеральные исследовательские центры (ФИЦ). В научных центрах Сибирского отделения (СО РАН) за 2015 - 2018 гг. были организованы ФИЦ нескольких видов: $\boldsymbol{a}$ ) объединение разнопрофильных институтов, ранее подведомственных разным академиям наук (РАН, РАМН, РАСХН), пример: ФИЦ Института цитологии и генетики (ИЦГ) ${ }^{3}$ и ФИЦ Красноярского научного центра (КНЦ) СО РАН, СО РАCХН и СО $\mathrm{PAMH}^{4}$; б) объединение институтов ранее подведомственных одной из академий - СО РАСХН или СО РАМН, пример: Сибирский Федеральный научный центр агробиотехнологий (СФНЦА РАН $)^{5}$; Томский национальный исследовательский медицинский центр (НИМЦ) ${ }^{6}$ и ФИЦ фундаментальной и трансляционной медицины $^{7}$;) объединение информационно-библиотечных учреждений ранее подведомственных двум академиям: СО РАН и РАСХН, пример: ГПНТБ СО РАН и СибНСХБ РАСХН. Процесс интеграции НИУ продолжается: в настоящее время организуется ФИЦ Тюменского научного центра СО РАН.

В результате реструктуризации НИУ - системы более высокого порядка трансформируется и система информационно-библиотечных подразделений, входящих в структуру институтов. Направления и темы научно-исследовательских работ, объединенных НИУ тесно связаны, научные сотрудники ФИЦ совместно работая по смежным темам, зачастую создают виртуальные научные структуры (научно-исследовательские группы, лаборатории, центры). Библиотечноинформационные потребности таких коллективов не может удовлетворить ни одна библиотека отдельно взятого учреждения, поэтому библиотеки НИУ, вошедших в состав ФИЦ, также объединяются. Например, пять библиотек институтов, вошедших в ФИЦ КНЦ СО РАН.

Все упомянутые научные структуры связаны между собой и могут существовать, сохраняться и самоорганизовываться при условии, если они обеспечены потоками ресурсов (ассигнований, коммуникаций, информации и оборудования). Однако в процессе реформирования науки были приняты законодательные документы ${ }^{8}$, не позволяющие объединять финансовые средства НИУ, в том числе на приобретение документов и других источников информации, а также их передачу с баланса на баланс научных организаций. Таким образом, с 2014 г. цен-

\footnotetext{
${ }^{1}$ Федеральный закон № 253-Ф3 «О Российской Академии наук, реорганизации государственных академий наук и внесении изменений в отдельные законодательные акты Российской Федерации»; Указ Президента № 735 «О Федеральном агентстве научных организаций» (ФАНО); Распоряжение Правительства РФ от 30 декабря 2013 г. № 2591-р об утверждении перечня организаций, подведомственных ФАНО России.

${ }^{2}$ Положение о Министерстве науки и высшего образования Российской Федерации Постановление Правительства РФ от 15.06.2018 г. № 682 .

${ }^{3} \mathrm{~B}$ состав ИЦГ вошли: Сибирский научно-исследовательский институт растениеводства и селекции РАСХН, НИИ медицинского профиля: Терапии и профилактической медицины (НИИТПМ) и Клинической и экспериментальной лимфологии (НИИКЭЛ), подведомственных ранее СО РАМН и управляющее учреждение «Сибирское отделение медицинских наук» [1].

${ }^{4}$ Помимо пяти НИУ КНЦ СО РАН в него вошли НИИ: Медицинских проблем Севера СО РАМН, Сельского хозяйства и экологии Арктики и Красноярский НИИ животноводства СО РАСХН, и некоторые другие. Все организации остаются самостоятельными, но имеют общее административное подразделение [2].

${ }^{5}$ СФНЦА РАН объединил девять НИИ и три филиала, ранее подведомственных СО РАСХН [3].

${ }^{6}$ НИИ кардиологии, НИИ психического здоровья, НИИ фармакологии и регенеративной медицины имени Е.Д. Гольдберга, НИИ медицинской генетики, НИИ акушерства, гинекологии и перинатологии) [4].

${ }^{7}$ К НИИ экспериментальной и клинической медицины присоединяются НИИ молекулярной биологии и биофизики, НИИ молекулярной патологии и патоморфологии и НИИ биохимии [

${ }^{8}$ Федеральный закон № 253-Ф3 «О Российской Академии наук, реорганизации государственных академий наук и внесении изменений в отдельные законодательные акты Российской Федерации», Указ Президента № 735 «О Федеральном агентстве научных организаций» (ФАНО) и Распоряжение Правительства РФ от 30 декабря 2013 г. № 2591-р об утверждении перечня организаций, подведомственных ФАНО России.
} 
тральные научные библиотеки (ЦНБ) информационно-библиотечных систем РАН: Библиотека академии наук (БАН), Библиотека по естественным наукам (БЕН), Институт научной информации по общественным наукам (ИНИОН), Государственная публичная научно-техническая библиотека (ГПНТБ) СО РАН, ЦНБ Уральского (УрО) и ЦНБ Дальневосточного (ДВО) отделений прекратили свою деятельность по одному из основных направлений централизованному комплектованию библиотек своих систем. В настоящее время НИУ из собственных ресурсов выделяют минимальные средства на приобретение необходимых документов, но как долго это может продолжаться?

В 2014-2018 гг. ежегодно сокращалось финансовое обеспечение всех ЦНБ РАН, в том числе на комплектование информационных ресурсов. Например, в 2016 г. бюджет БЕН РАН по сравнению с дореформенным 2013 г. был уменьшен на 60 млн руб., а с 2017 г. ЦНБ РАН были и вовсе лишены государственной поддержки: выделение средств на комплектование фондов библиотек РАН отечественными и зарубежными документами прекратилось. Это решение руководства объяснялось развертыванием национальной подписки на доступ к сетевым версиям зарубежных научных журналов и базам данных. В результате ЦНБ РАН потеряли возможность приобретения зарубежных источников информации, не входящих в национальную подписку. В настоящее время единственным источником поступлений отечественных научных публикаций в информационные центры и главные библиотеки РАН является «обязательный экземпляр» [6].

Очевидно, что такое решение Министерства науки и высшего образования Российской Федерации (РФ) вызвано взятым курсом на информационное обеспечение науки в виртуальном пространстве. Данное предположение подтверждается тем, что в мае 2019 г. Советом по цифровому развитию и информационным технологиям Минобрнауки РФ была одобрена Концепция Единой цифровой платформы науки, изложенная в докладе «Цифровая трансформация науки». Суть Концепции состоит в создании системы управления сервисами научной инфраструктуры коллективного пользования для проведения совместных исследований. При помощи данной системы всем пользователям (представителям научного сообщества, включая лаборатории и отдельных российских и зарубежных ученых, представителям органов государственной власти и бизнеса) будет предоставлен доступный набор инструментов и сервисов. «Платформа» позволит организовывать и проводить совместные исследования в удаленном доступе с возможностью формирования виртуальных команд и лабораторий для реализации проекта любой сложности, поскольку обеспечит пользователям доступ к заказу услуг, в том числе к оцифрованным коллекциям и банкам данных организаций, выполняющих научные исследования и разработки. Это будет своего рода «маркетплейс ${ }^{1}$, с большим набором пользовательских сервисов, в том числе центров коллективного пользования, для групп учёныхисследователей, - российский «Амазон» ${ }^{2}$ для сферы науки» [7]. После ввода в эксплуатацию данной системы останутся ли востребованными академические библиотеки, поскольку можно предположить, что они потеряют большую часть своих виртуальных пользователей.

Парадигма библиотечного обслуживания учёных-исследователей действительно изменилась, так как предоставление онлайновых электронных ресурсов делает бумажные издания менее востребованными, хотя затраты на их производство, распространение и хранение несопоставимо больше, чем на аналогичные процессы в цифровой среде. В результате в библиотеках РАН происходит перманентное сокращение показателей традиционного библиотечного обслуживания (читателей, посещаемости и книговыдачи) и в тоже время увеличивается число пользователей и обращений - в среде электронной.

\footnotetext{
${ }^{1}$ Маркетплейс - оптимизированная онлайн-платформа по предоставлению продуктов и услуг. Википедия. URL : https://ru.wikipedia.org/wiki/Маркетплейс.

${ }_{2}^{2}$ Американская транснациональная компания, специализирующаяся на электронной коммерции, облачных вычислениях и искусственном интеллекте.
} 
Тенденции, сложившиеся в деятельности академических библиотек, были раскрыты методом сравнительного анализа статистических показателей на примере библиотечной системы СО РАН за период реформирования науки (2014 и 2018 гг.). Анализ показал сокращение числа библиотек НИУ СО РАН с 70 до 63: пять библиотек были объединены в процессе организации Федерального исследовательского центра (ФИЦ) Красноярского научного центра (КНЦ), а две закрыты. Помимо объединения и закрытия библиотек, наметилась устойчивая тенденция сокращения занимаемых ими площадей. Фонды 27 \% библиотек НИУ СО РАН насчитывают от 200 до 400 тыс. экз., поэтому проблема их размещения и сохранения остаётся актуальной и требует принятия решений. Совокупный документный фонд библиотек на 1.01 .19 г. составляет 5 млн 203 тыс. экз. Общее поступление новых документов в фонды библиотек в 2018 г. (в сравнении с показателями 2013 г. - последнего года централизованного комплектования через ГПНТБ СО РАН) сократилось на $74 \%$; зарубежных изданий - на $79 \%$. С 2014 г. институты выделяют библиотекам денежные средства только на подписку отечественной периодики, а зарубежные издания поступают исключительно «в дар» от сотрудников институтов. В 2018 г. поступление зарубежных документов в фонды библиотек НИУ СО РАН в сравнении с 2013 г. составило 21,5 \%. Отсутствие новых поступлений научных документов в фонды библиотек существенно снизило уровень информационного обеспечения учёных исследователей.

Общее число пользователей в 2018 г., по сравнению с 2013 г., сократилось на $15 \%$, абонентов МБА - на $26 \%$, читателей - физических лиц стало меньше на $19 \%$, а посещаемость библиотек снизилась наполовину. В тоже время на 63,5 \% увеличилось число пользователей библиотек, зарегистрированных через электронные сети, и одновременно количество их обращений online увеличилось в 2,5 раз. Общая книговыдача документов составила $50 \%$, выдача зарубежных изданий $-27 \%$, при этом количество обращений к зарубежным электронным ресурсам увеличилось в 6,5 раз.

Библиотечный персонал СО РАН за годы реформ сократился на 36 человек, на 25 (17\%) сотрудников стало меньше с высшим образованием, с высшим библиотечным - на 19 (21\%).В отдельных НИУ библиотечные ставки были сокращены, а библиотекари переведены на инженерные должности ${ }^{1}$. Штаты 23 библиотек (36 \%) состоят из одного сотрудника, при этом функциональные обязанности библиотекарей расширяются и усложняются, в том числе наукометрическими формами работы. Например, библиотекари корректируют профили НИУ в системах SCIENCEINDEX и eLIBRARY.RU, вводят сведения о новых сотрудниках и их публикациях, что позволяет увеличивать показатели цитирований, участвуют в определении индексов Хирша и рейтинга журналов, лабораторий и научных центров по публикациям и цитированию работ сотрудников НИУ. Большинство библиотечных специалистов академических библиотек отличает от библиотекарей других систем высокий профессионализм, способности быстро находить, отбирать и предоставлять нужную информацию пользователям, осваивать новые формы работы и цифровые технологии, значимость которых возрастает с каждым днём.

В результате реформирования РАН трансформировалась система научных учреждений и библиотек, подсистемой которой они являются. Организованы Федеральные исследовательские центры, объединившие разнопрофильные НИУ и библиотеки. Прекращена государственная, в том числе финансовая поддержка формирования фондов ЦНБ РАН и библиотек институтов. Уникальность фондов академических библиотек без новых поступлений, в том числе профильных зарубежных научных изданий, очень скоро будет утрачена, и они превратятся в архивы. Все возрастающие объемы использования учеными-исследователями электронных ресурсов в среде виртуальной, способствуют стабильному сокращению всех форм традиционного библиотечного обслуживания. Министерством науки и высшего образования РФ одобрена Концепция Единой цифровой платформы науки, внедрение которой в эксплуатацию, может поставить под сомнение необходимость функционирования академических библиотек.

${ }^{1}$ Институт систем информатики Новосибирского научного центра и Лимнологический институт Иркутского научного центра. 
Таким образом, ускоряется эволюционный процесс перехода от традиционного информационного сопровождения науки в цифровую среду, в которой нет необходимости приобретать источники информации на бумажных носителях, виртуальные (оцифрованные) фонды библиотек не требуют площадей для хранения документов, а пользователи - читальных залов для работы с информацией.

\section{Список литературы}

1. ФИЦ ИЦиГ СО РАН расширяет структуру. - Текст : электронный // Гос. публ. науч-тех. б-ка Сиб. отд-я Рос. академии наук. Новости сибирской науки : [сайт]. - Новосибирск, 2019. - URL: http://www.sibscience.info/ru/institutes/itsig-stanet-esche-b-18102016 (дата обращения: 26.04.2019).

2. Институты и организации [Федерального исследовательского центра «Красноярский научный центр СО РАН»]. - Текст : электронный // ФГБНУ «Федеральный исследовательский центр “Красноярский научный центр Сибирского отделения Российской академии наук” (КНЦ СО РАН, ФИЦ КНЦ СО РАН) : [сайт]. - Красноярск, 2019. - URL: http://old.ksc.krasn.ru/institutes/ (дата обращения: 03.05.2019).

3. О создании Федерального государственного бюджетного учреждения науки Сибирского федерального научного центра агробиотехнологий Российской академии наук (СФНЦА РАН). - Текст : электронный // ФГБУН «Сибирский федеральный научный центр агробиотехнологий Российской академии наук» (СФНЦА РАН): [сайт]. - Краснообск, 2010-. - URL: http://www.sorashn.ru/index.php?id=2257\&tx_ ttnews[tt_news] $=3263 \& t x \_t$ tnews[backPid] $=1362 \& \mathrm{cHash}=4199956 \mathrm{e} 01468592 \mathrm{cf6} 68 \mathrm{bbcc} 1 \mathrm{cfce} 123$ (дата обращения: 25.04.2019).

4. Томский национальный исследовательский медицинский центр Российской академии наук : официальный сайт. - Томск. - URL: http://www.tnimc.ru/ (дата обращения 4.05.2019). - Текст : электронный.

5. НИИ объединились в один исследовательский центр медицины. - Текст : электронный // Российская академия наук : [офиц. сайт]. - Москва, 2019. - URL: http://www.ras.ru/news/shownews. aspx?id=078dbe61-0035-4017-b5ac-100d66e39c47 (дата обращения 31.05.2019).

6. Латышев, А. Реформа РАН: между прошлым и будущим.-Текст : электронный / А. Латышев, И. Гительзон, Н. Каленов // Поиск. - 2018. - № 26. - URL: https://www.poisknews.ru/magazine/37047/ (дата обращения: 16.04.2019).

7. Павлов, Д. Сырьевые целевые. Программы коммерческих компаний по поддержке молодёжи отражают характер экономики. - Текст : электронный // Поиск. - 2011. - № 37. - URL : http://www.poisknews.ru/archive/2018/350/ (дата обращения: 15.05.2019).

8. Цифровизация как драйвер развития науки и образования. - Текст : электронный // Гос. публ. научтех. б-ка Сиб. отд-я Рос. академии наук. Новости сибирской науки : [сайт]. - Новосибирск, 2019. - URL: http://www.sib-science.info/ru/news/tsifrovizatsiya-kak-drayver-02052019 (дата обращения: 13.05.2019).

Tatiana V. Dergilyova, Ph. D. in Pedagogics State Public Scientific and Technical Library of the Siberian Branch of the Russian Academy of Sciences (Novosibirsk, Russia) dergileva@spsl.nsc.ru

\section{ACADEMIC LIBRARIES IN THE CONTEXT OF TRANSFORMATION AND DIGITALIZATION OF SCIENCE}

Аннотация. Organizational changes in system of Russian state academies of sciences, creation of federal research centers within the structure of Federal Agency of Research Organizations entailed noticeable transformation academic sector of the domestic science that have caused moves in views on information supporting of research work and financing exit from state patronage in acquisition of documents for central scientific libraries of institutions of the Russian Academy of Sciences. Russian Ministry of Science and Higher Education took a ply for forced integration of digital technologies with spheres of scientific knowledge. The author of the article discloses the key tendencies in information support of scientific research work taking into account an experience of library system of the Siberian Branch of the Russian Academy of Sciences (Novosibirsk, Russia); states inverse relationship between scientists' usage of remote e-resources and their demand of a complex of information and bibliographical services offered by a today's scientific library.

Key words: scientific institutions, scientific libraries, libraries of institutions of the Russian Academy of Sciences, structure of library systems, information support of scientific labor, digitalization of science. 